\title{
Aplicação da Robótica Educacional no Ensino das Relações Métricas do Triângulo Retângulo
}

\author{
Marden Eufrasio dos Santos, MPET/IFAM, nedram.santos@gmail.com \\ Andréa Pereira Mendonça, MPET/IFAM, andrea.ifam@gmail.com
}

\begin{abstract}
Resumo. Pode Robótica Educacional ajudar no desenvolvimento de habilidades matemáticas em estudantes da Educação Básica? Neste artigo nós avaliamos tal potencial, considerando o estudo das relações métricas do triângulo retângulo e o desenvolvimento de duas habilidades: (i) identificação dos elementos geométricos em uma representação gráfica; (ii) elaboração, com base nos elementos envolvidos no problema, da equação algébrica e sua resolução para fornecer respostas aos problemas propostos. Para isto, nós planejamento e realizamos um estudo cujos resultados são discutidos neste artigo e demonstram que a Robótica se mostrou mais efetiva no desenvolvimento da primeira habilidade. Este trabalho resultou também em um caderno, disponível na Web, para auxiliar professores que desejam integrar a Robótica no estudo de assuntos de Geometria no currículo da Educação Básica.
\end{abstract}

Palavras-chave: Robótica Educacional. Aprendizagem Matemática. Relações Métricas do Triângulo Retângulo. Alinhamento Construtivo.

\section{Application of Educational Robotics in the Metric Relations in Right Triangle Teaching}

\begin{abstract}
Can Educational Robotics support the development of mathematical skills in Basic Education students? In this paper we evaluated such potential considering the study of the metric relations in right triangle by taking into consideration two different skills: (i) identification of geometrical elements in a graphical representation; and (ii) elaboration, through algebraic notation, of elements in the problem header and its resolution with algebra. To do so, we planned and performed a study whose results are discussed in this paper. The results emphasize that Educational Robotics has been more effective in the development of the first skill. Besides the planning, execution and results from this study, we also present some guidelines and supporting resources to other teachers that would like to integrate Geometry and Educational Robotics in Basic Education curriculum.
\end{abstract}

Keywords: Educational Robotics. Mathematics Learning. Metric Relations in Right Triangle. Constructive Alignment.

\section{Introdução}

As Relações Métricas do Triângulo Retângulo constituem-se como um importante conteúdo da Geometria no Ensino Fundamental e a base para o estudo de Trigonometria no Ensino Médio (BRASIL, 1998), apresentando grande potencial de aplicação na resolução de problemas matemáticos e do cotidiano.

No Ensino Fundamental esse conteúdo é ministrado a alunos do $9^{\circ}$ ano, geralmente, a partir do $3^{\circ}$ bimestre letivo. Para resolver os problemas propostos neste domínio, são requeridos dos alunos, principalmente, as seguintes habilidades: (i) identificação dos elementos geométricos em uma representação gráfica (doravante denominada Habilidade 1); (ii) elaboração, com base nos elementos envolvidos na definição dos problemas, da equação algébrica e sua resolução para fornecer respostas aos problemas propostos (doravante denominada Habilidade 2). 
O desenvolvimento destas habilidades em sala de aula representa grande desafio para os professores na medida em que devem planejar o ensino de Geometria levando em consideração a percepção e compreensão dos objetos pelos alunos - espaço físico, figuras geométricas e representações gráficas, a manipulação destes objetos e ainda o desenvolvimento de um conjunto de estratégias que os permitam elaborar conjecturas e testá-las (RESENDE; MESQUISTA, 2013; PEREIRA; OLIVEIRA, 2016).

Fundamentados nesta perspectiva, nós desenvolvemos um estudo sobre a integração de Robótica Educacional no ensino das Relações Métricas do Triângulo Retângulo. A Robótica Educacional caracteriza-se pela montagem e programação de modelos robóticos visando a resolução de problemas. A robótica educacional tem sido considerada importante para o ensino das Ciências, da Matemática, Tecnologias, Informática, e também de atividades interdisciplinares (COSTA JÚNIOR; GUEDES, 2015).

Em nosso estudo, nós elaboramos um planejamento de ensino fundamentado no Alinhamento Construtivo (BIGGS; TANG, 2011) que primou pela resolução de problemas como eixo organizador do processo de ensino e aprendizagem de Matemática (BRASIL, 1998). A Robótica Educacional foi utilizada como recurso para permitir aos alunos manusear e construir modelos robóticos físicos, assim como para testar e expressar suas soluções para os problemas propostos.

O planejamento de ensino foi avaliado por meio de um estudo de caso realizado com alunos do $9^{\circ}$ ano do ensino fundamental da escola Deyse Lammel Hendges, situada no munícipio de Presidente Figueiredo, no Amazonas. Os fundamentos deste estudo, o percurso metodológico, assim como os resultados obtidos são apresentados nas próximas seções.

\section{Quadro Teórico}

Nosso estudo, que teve como elemento fundamental o planejamento de ensino, está conceitualmente embasado no Alinhamento Construtivo e na Robótica Educacional, ambos descritos a seguir.

\subsection{Alinhamento Construtivo}

O Alinhamento Construtivo tem suas raízes no Construtivismo e na Teoria do Curriculum. O Construtivismo é entendido por Biggs e Tang (2011) como a base para pensar sobre o ensino, pois enfatiza a construção do conhecimento a partir das atividades realizadas pelos estudantes. Assim, o termo Construtivo refere-se a ideia de que são as atividades realizadas pelos estudantes que definem o que é aprendido e Alinhamento é um princípio da Teoria do Curriculum que diz que as tarefas da avaliação devem estar alinhadas ao que se pretende que seja aprendido. Desta forma, ensino e avaliação devem estar alinhados aos resultados pretendidos da aprendizagem.

O planejamento, segundo o Alinhamento Construtivo, concentra-se em três conceitos principais: Resultados Pretendidos da Aprendizagem (Intended Learning Outcome - ILO), Atividades de Ensino e Aprendizagem (Teaching Learning Activities - TLA) e Tarefas de Avaliação (Assessment Task - AT) e estes podem ser alinhados tomando como auxílio a Taxonomia SOLO.

A Taxonomia SOLO (Structure of the Observed Learning Outcome), ilustrada na Figura 1, possui cinco níveis diferentes e cada nível torna-se uma base sobre a qual a aprendizagem futura é construída. De um ponto de vista prático, a resposta que um indivíduo produz, durante a realização de certa tarefa, apresenta uma certa qualidade, sendo possível atribuir-lhe uma categoria, analisando apenas o seu desempenho (CEIA; FILIPE; SANTOS, 2011).

Assim, uma resposta no nível uniestrutural demonstrará que o estudante é capaz de lidar 
apenas com um aspecto relevante ou conhecido da pergunta ou problema e usá-lo na produção de uma resposta válida, enquanto em uma resposta no nível multiestrutural serão apresentados vários aspectos relevantes, contudo de forma independente, sem as devidas conexões para a formação do todo. No nível relacional, por sua vez, a resposta mostrará que o estudante obteve uma melhoria qualitativa, sendo capaz de estabelecer relações entre as várias informações e como elas podem se encaixar para formar um todo. Em uma resposta no nível abstrato estendido, nota-se mais melhorias qualitativas e demonstram que os estudantes são capazes de analisar um problema de muitas perspectivas diferentes, lidar com informações hipotéticas e de generalizar. Ao alcançar este nível, os estudantes podem, por exemplo, generalizar, criar hipóteses, teorizar e transferir a teoria para um novo domínio (BRABRAND; DAHL, 2007; CEIA; FILIPE; SANTOS, 2011).

Figura 1. Taxonomia SOLO.

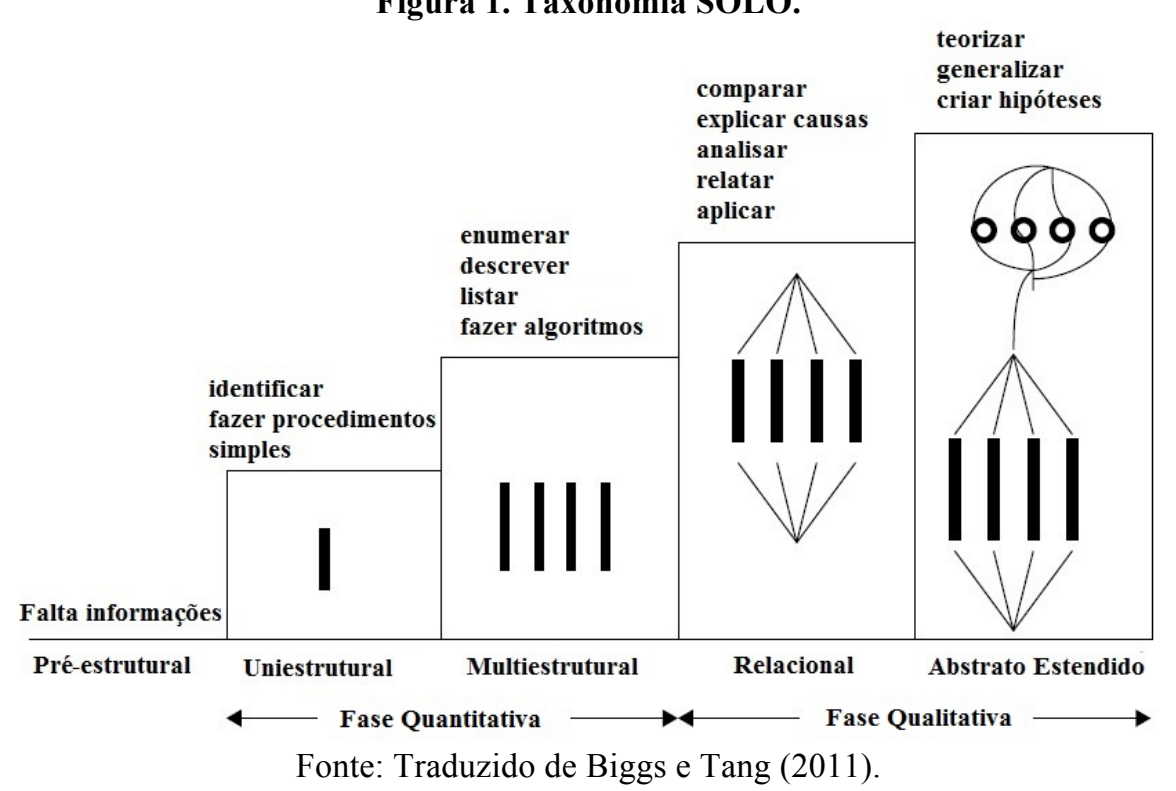

Retomando os conceitos principais do Alinhamento Construtivo, podemos compreender o resultado pretendido da aprendizagem como o objetivo da aprendizagem. Portanto, deve esclarecer o que os estudantes devem ser capazes de realizar depois de terem passado pelas atividades de ensino e que não podiam fazer anteriormente, sendo expressos na forma de verbo (BIGGS; TANG, 2011). Alguns verbos típicos de cada nível da taxonomia são apresentados na parte superior da Figura 1.

As atividades de ensino e aprendizagem devem especificar o que os professores e estudantes fazem, sem perder de vista que é a ação do aluno que determina o alcance dos resultados pretendidos da aprendizagem. Portanto, as atividades de ensino e aprendizagem devem ser planejadas de modo que os estudantes tenham o incentivo necessário para alcançar o nível cognitivo que os objetivos requerem.

A tarefas de avaliação, por sua vez, deve ser planejada de modo que permita informar quão bem os estudantes alcançaram os resultados pretendidos da aprendizagem. Para projetar avaliações adequadas é necessário levar em consideração um conjunto de aspectos, tais como, formato da avaliação, tipo de conhecimento envolvido e o estabelecimento de critérios de avaliação.

Com respeito a este último aspecto, Biggs e Tang (2011) sugerem uma abordagem que conjuga aspectos qualitativos e quantitativos com o uso de rubricas (rubrics), que podem ser entendidas como um recurso que estabelece as expectativas específicas para uma tarefa. Rubricas dividem uma tarefa em suas partes componentes e fornecem uma descrição detalhada 
de cada uma delas (STEVENS; LEVI, 2005) e seu uso pelo professor ajuda a manter a confiança e a estabilidade na correção, assim como é um recurso para prover feedback aos estudantes.

\subsection{Robótica Educacional}

A Robótica Educacional surge a partir do trabalho de Seymour Papert na década de 60. Crítico do uso da tecnologia como mera reprodutora de conteúdos, Papert, fundamentado no Construtivismo de Jean Piaget, cunhou o termo Construcionismo para designar uma filosofia educacional na qual o aprendiz constrói, por intermédio do computador, o seu próprio conhecimento (PAPERT, 2008).

Na perspectiva do Construcionismo, o computador é entendido como um instrumento para a aprendizagem e a linguagem de programação como um meio para a criação e expressão de ideias através do computador. Para concretizar essa filosofia Construcionista, Papert criou a Linguagem LOGO e a Robótica Educacional, provendo exemplos significativos de sua aplicação na aprendizagem de conteúdos da Matemática (PAPERT, 2008).

A Robótica Educacional pode ser compreendida como um modelo ou proposta didática que utiliza os fundamentos e recursos tecnológicos da robótica convencional, através de kits didáticos, para auxiliar na aprendizagem e resolução de problemas. Em nosso trabalho, utilizamos o kit didático LEGO Mindstorms EV3, fabricado e mantido pela LEGO Group. Os kits didáticos são compostos por peças estruturais plásticas ou de alumínio, componentes eletrônicos e mecânicos, além de recursos de programação de computadores que tornam possíveis a montagem de modelos robóticos autônomos, capazes de mover-se e atuarem em diversas situações para a resolução de problemas cotidianos.

Com a utilização da Robótica Educacional os estudantes podem desenvolver estratégias para selecionar dados relevantes para o entendimento do problema, organizá-los de forma lógica, além de identificar, analisar, implementar e testar possíveis soluções.

Estas habilidades integram o que atualmente é chamado de pensamento computacional e que para Blinkstein (2008) pode ser entendido como a habilidade de transformar teorias e hipóteses em modelos e programas de computador, executá-los, depurá-los, e utilizá-los para redesenhar processos produtivos, realizar pesquisas científicas ou mesmo otimizar rotinas pessoais. É uma das mais importantes habilidades para os cidadãos do século XXI.

Para desenvolver esse conjunto de habilidades e ainda favorecer a aprendizagem das Relações Métricas do Triângulo Retângulo, elaboramos um planejamento de ensino que teve como eixo organizador a resolução de problemas integrado a Robótica Educacional, conforme será apresentado na próxima seção.

\section{Planejamento de Ensino}

Nosso planejamento de ensino foi organizado em três (03) módulos, totalizando 32 horas/aula. O Módulo I, chamado Nivelamento, teve por objetivo capacitar os alunos para o uso do kit de Robótica Educacional LEGO Mindstorms EV3 e trabalhar os conteúdos que são prérequisitos para o estudo das Relações Métricas do Triângulo Retângulo: retas e segmentos de retas, figuras geométricas planas, triângulo e semelhança de triângulos. A capacitação dos estudantes para o uso de Robótica foi necessária porque nossos alunos não possuíam qualquer experiência anterior com Robótica Educacional.

O Módulo II, de Fundamentos, tratava de atividades práticas com o uso da Robótica Educacional cujo enfoque eram os conteúdos matemáticos de fundamentação sobre as Relações Métricas do Triângulo Retângulo, tipos de relações e Teorema de Pitágoras. 
O Módulo III, Avançado, teve por objetivo desenvolver atividades de demonstrações das relações métricas e teoremas, com enfoque no Teorema de Pitágoras, utilizando-se problemas de matemática e técnicas de robótica mais avançadas.

Para cada módulo, os conteúdos foram trabalhados em torno da resolução de um problema tema relacionado a uma temática amazônica. No Módulo I, o problema tema foi intitulado Pecuária Amazônica e era relacionado à criação de animais em pastos regionais. A ideia central era fazer um robô transportar alimentos para os animais, percorrendo o circuito Fazenda Amazônica (Figura 2). Para a solução deste problema, os estudantes deveriam construir um modelo robótico chamado robô transportador, que se deslocava entre quatro pontos da fazenda: o estacionamento de transporte (Ponto A da Figura 2), o armazém (Ponto B da Figura 2), o celeiro (Ponto C da Figura 2) e o curral de higienização (Ponto D da Figura 2).

Figura 2. Circuito e Modelo Robótico para o Problema Tema Pecuária Amazônica.

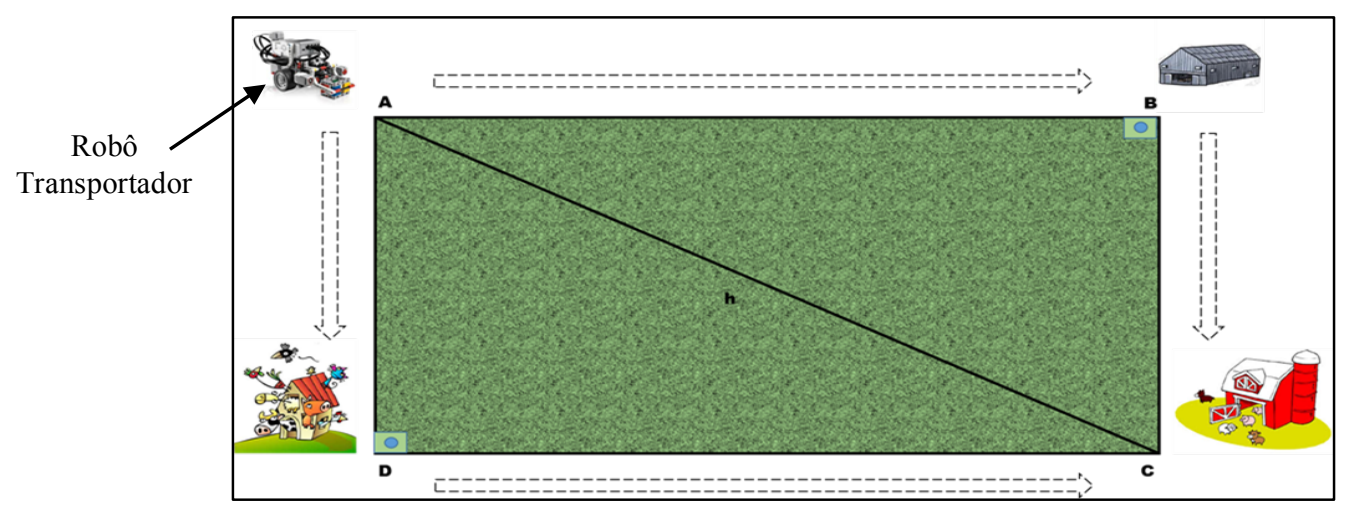

Fonte: Elaborado pelos autores.

No Módulo II, o problema tema foi intitulado A Harpia da Amazônia. Neste problema a Harpia ou Gavião Real da Amazônia é apresentado aos estudantes através de um modelo robótico que simula um veículo de vigilância terrestre, interagindo com um circuito que chamamos de Santuário da Harpia. As atividades práticas deste problema abordaram o deslocamento do robô vigilante nas áreas de preservação da Harpia, no berçário e na região de ocorrência de caça. A ideia central era utilizar o robô vigilante para combater as possíveis equipes de caça detectadas na região, garantindo assim a integridade do berçário com consequente preservação dessa espécie de ave amazônica.

O problema tema do Módulo III foi intitulado O Serpentário. Este problema enfatizava uma das espécies de serpente amazônica, a Sucuri. Nas atividades práticas deste problema, o modelo robótico utilizado simulava a própria serpente em deslocamento no seu habitat natural. A serpente robótica se deslocava nas áreas de reprodução, no ninho e nas áreas de ocorrência dos seus predadores naturais, contextualizadas por um circuito que definimos como Habitat das Serpentes. A ideia central era estudar os hábitos de deslocamento e reprodução dessas serpentes, visando a coleta de dados científicos.

Cada problema tema era composto por dois conjuntos de questões relacionadas a habilidade que pretendíamos desenvolver. No caso da Habilidade 1, as questões envolviam a identificação, nos circuitos, dos segmentos de retas, os tipos de figuras geométricas formadas, identificação de ângulo agudos e retos, entre outros. No caso da Habilidade 2, as questões envolviam, por exemplo, o cálculo da distância percorrida de um ponto a outro, cálculo da área e perímetro e custo de energia gasto pelo robô em seu deslocamento.

Rubricas avaliativas, baseada na Taxonomia SOLO, foram construídas para avaliar as respostas dos alunos aos problemas propostos. No Quadro 1, apresentamos a rubrica criada para a Habilidade 1 - Identificação dos elementos geométricos em uma representação gráfica. Uma rubrica com estrutura similar foi criada para a Habilidade 2. 
Como pode ser observado no Quadro 1, a escala da rubrica foi construída com base na Taxonomia SOLO, contendo os níveis uniestrutural, multiestrutural e relacional. No escopo deste trabalho, o nível abstrato estendido não foi considerado, porque ao avaliarmos alguns livros didáticos e atividades propostas para alunos do $9^{\circ}$ ano, verificamos que não é comum o desenvolvimento das habilidades típicas do nível abstrato estendido. Assim, planejamos o nosso estudo com o propósito de que, ao final, os alunos pudessem alcançar o nível relacional em plenitude (conceito ótimo). Cabe destacar ainda, que as rubricas também levaram em consideração as possibilidades de respostas incompletas dadas pelos alunos, por exemplo, quando eles conseguem identificar apenas parte dos elementos e propriedades geométricas solicitados nos problemas propostos.

Quadro 1. Rubrica Avaliativa - Identificação dos elementos geométricos.

\begin{tabular}{|c|c|c|c|c|}
\hline \multirow{2}{*}{ Conceito: } & \multirow{2}{*}{$\begin{array}{c}\text { Uniestrutural } \\
\text { Insuficiente }\end{array}$} & \multirow{2}{*}{$\begin{array}{c}\text { Multiestrutural } \\
\text { Regular }\end{array}$} & \multicolumn{2}{|c|}{ Relacional } \\
\hline & & & Bom & ÓTIMO \\
\hline $\begin{array}{l}\text { Identificação dos } \\
\text { elementos } \\
\text { geométricos em } \\
\text { uma representação } \\
\text { gráfica }\end{array}$ & $\begin{array}{l}\text { Identifica alguns } \\
\text { elementos e } \\
\text { propriedades em } \\
\text { figuras geométricas } \\
\text { simples }{ }^{1} \text {. }\end{array}$ & $\begin{array}{l}\text { Identifica todos os } \\
\text { elementos e } \\
\text { propriedades em } \\
\text { figuras geométricas } \\
\text { simples. Mas, } \\
\text { consegue } \\
\text { identificar apenas } \\
\text { alguns elementos e } \\
\text { propriedades } \\
\text { quando são } \\
\text { consideradas } \\
\text { figuras } \\
\text { complexas }{ }^{2} .\end{array}$ & $\begin{array}{l}\text { Identifica todos os } \\
\text { elementos e } \\
\text { propriedades } \\
\text { geométricas } \\
\text { solicitadas, } \\
\text { considerando } \\
\text { figuras simples e } \\
\text { complexas. Porém, } \\
\text { consegue } \\
\text { relacionar apenas } \\
\text { parte destes com a } \\
\text { notação algébrica } \\
\text { adequada. }\end{array}$ & $\begin{array}{l}\text { Identifica todos os } \\
\text { elementos e } \\
\text { propriedades } \\
\text { geométricas } \\
\text { solicitadas, } \\
\text { considerando } \\
\text { figuras simples e } \\
\text { complexas, } \\
\text { relacionando-as } \\
\text { adequadamente a } \\
\text { notação algébrica. }\end{array}$ \\
\hline
\end{tabular}

Fonte: Elaborado pelos autores.

Na próxima seção descrevemos o percurso metodológico para avaliação da efetividade desta proposta de ensino, considerando a sua execução com alunos do $9^{\circ}$ do ensino fundamental.

\section{Percurso Metodológico}

Participaram do estudo de caso trinta (30) estudantes do $9^{\circ}$ ano do Ensino Fundamental da escola Deyse Lammel Hendges, situada no munícipio de Presidente Figueiredo, no Amazonas. Neste estudo, buscamos responder as seguintes questões de pesquisa (QP):

QP1: O uso de Robótica Educacional nas aulas de Matemática possibilitou aos estudantes melhorarem seu desempenho com respeito a Habilidade 1?

QP2: O uso de Robótica Educacional nas aulas de Matemática possibilitou aos estudantes melhorarem seu desempenho com respeito a Habilidade 2?

QP3: Quais dificuldades e limitações são mais frequentes nos alunos ao lidarem com a Robótica Educacional na Aprendizagem das Relações Métricas do Triângulo Retângulo, considerando as habilidades anteriormente mencionadas?

\footnotetext{
${ }^{1}$ Figuras simples são figuras com formas geométricas mais facilmente identificáveis e que requerem pouca interpretação de contexto para identificação dos elementos e propriedades geométricas. Um exemplo é apresentado na Figura 2.

${ }^{2}$ Figuras complexas são aquelas compostas por outras figuras geométricas e que exigem maior interpretação de contexto para identificação dos elementos e propriedades geométricas.
} 
A execução deste estudo deu-se no contra turno escolar e os alunos foram organizados em equipes de três estudantes, compondo um total de dez (10) equipes. Para as atividades de robótica, os membros da equipe foram organizados em torno de três (03) funções: (i) o organizador - responsável pelo planejamento e gerenciamento das atividades do grupo; (ii) o construtor - responsável pela montagem do modelo robótico; e (iii) o programador responsável por criar os programas que dariam movimento aos modelos robóticos. A cada início de módulo era realizada a rotatividade de funções entre os membros do grupo. Ao final do estudo, cada um dos estudantes desempenhou uma vez, cada uma das funções propostas.

Neste estudo, houve o trabalho conjunto de dois professores - o de Robótica e o de Matemática. Ambos cooperavam par dar suporte e orientação aos alunos quanto aos conteúdos específicos sobre Relações Métricas do Triângulo Retângulo e sobre os aspectos técnicos pertinentes a montagem, programação e testes dos modelos robóticos. Cabia também aos professores prover auxílio no trabalho e organização das equipes.

Embora a resolução dos problemas temas fosse realizado em equipes, havia ao final de cada módulo uma avaliação, denominada avaliação modular, a ser respondida individualmente pelos estudantes, com duração de $2 \mathrm{~h}$. Cada avaliação modular era composta por questões comumente presentes em livros e avaliações destinadas a alunos do ensino fundamental. Assim, poderíamos observar como a aprendizagem dos alunos por meio dos problemas temas e Robótica se revelaria quando submetidos a questões mais convencionais de Matemática. Também realizamos um pré e pós teste, com o objetivo de avaliar o desempenho dos alunos, antes e depois da intervenção. A seguir, apresentamos os resultados do estudo.

\section{Resultados e Discussões}

Com respeito a questão de pesquisa 1 (QP1), apresentamos na Figura 3 (lado esquerdo) o resultado do desempenho dos estudantes no pré e pós-teste para a Habilidade 1. Como pode ser observado, a intervenção resultou em um ganho significativo na aprendizagem, tendo o pósteste revelado que, ao final do estudo, $86,2 \%$ dos estudantes haviam alcançado o nível relacional para a Habilidade 1, enquanto que no pré-teste, 96,7\% dos estudantes concentravam-se no nível uniestrutural.

Figura 3. Resultado do Pré e Pós-Teste para as Habilidades I e II.

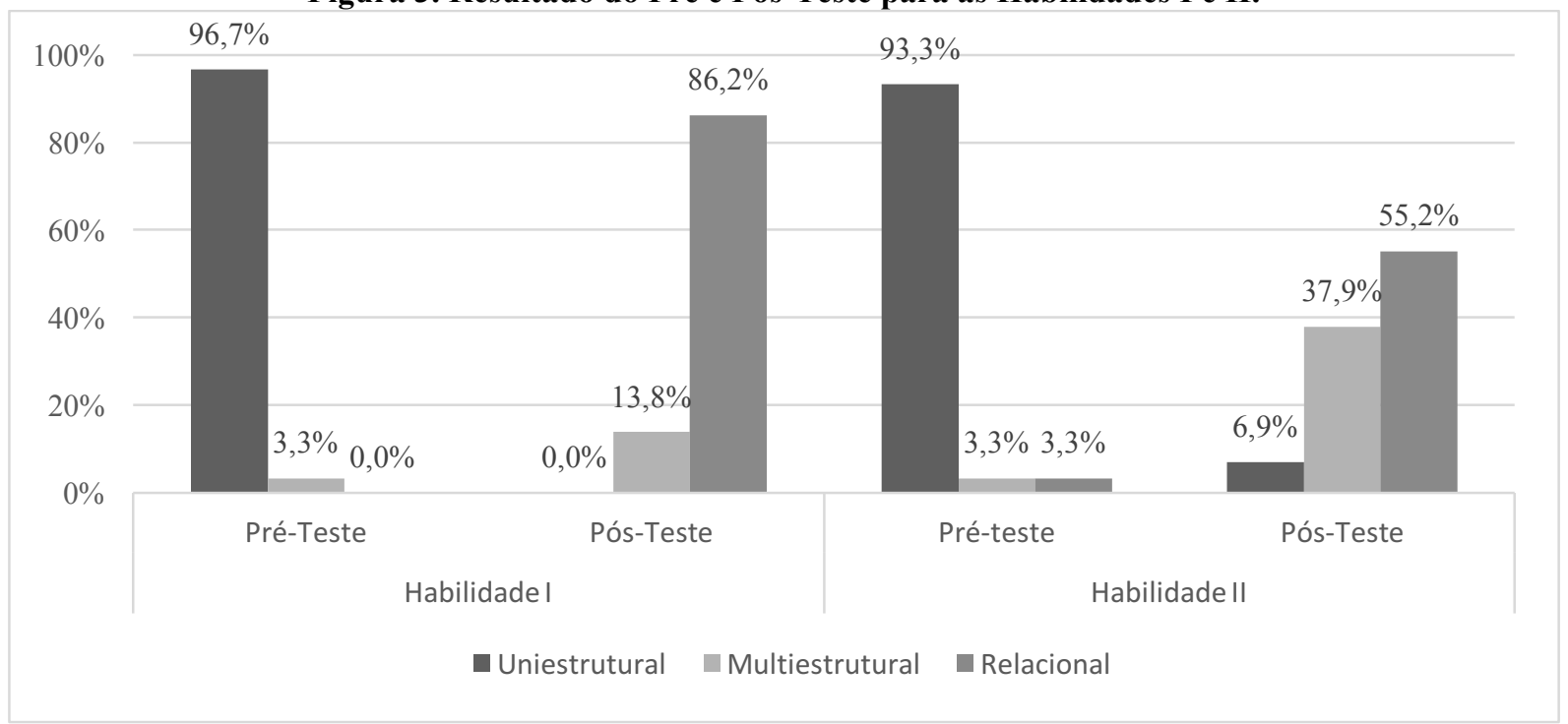

Fonte: Elaborado pelos autores. 
Uma perspectiva mais detalhada dos ganhos de aprendizagem pode ser visualizada na Figura 4 (lado esquerdo), na qual apresentamos o rendimento dos alunos nas Avaliações Modulares I, II e III para a Habilidade 1. Como pode ser observado, ao final do Módulo I menos de $20 \%$ da turma alcançou o nível relacional, sendo que não houve neste nível estudantes que alcançaram o conceito ótimo. Gradativamente há um avanço dos estudantes, sendo o melhor desempenho verificado no Módulo III, quando $89,7 \%$ dos estudantes alcançaram o nível relacional. Destes, 79,3\% alcançaram o conceito ótimo, portanto foram capazes de identificar todos os elementos e propriedades geométricas solicitadas, considerando figuras simples e complexas, relacionando-as adequadamente a notação algébrica.

Em nossa avaliação, o aumento gradativo no desempenho dos alunos quanto a Habilidade 1 foi favorecida pela manipulação dos robôs (objetos concretos) e também pelo desenvolvimento de ações repetitivas pelos alunos. Por exemplo, para que o robô realizasse o trajeto, os alunos tiveram que fazer vários testes e estas "idas e vindas" acabavam por exigir dos alunos maior percepção do circuito e da associação das partes do circuito com os elementos e propriedades geométricas, favorecendo, assim, a aprendizagem.

Figura 4. Resultado das Avaliações Modulares paras as Habilidades I e II.

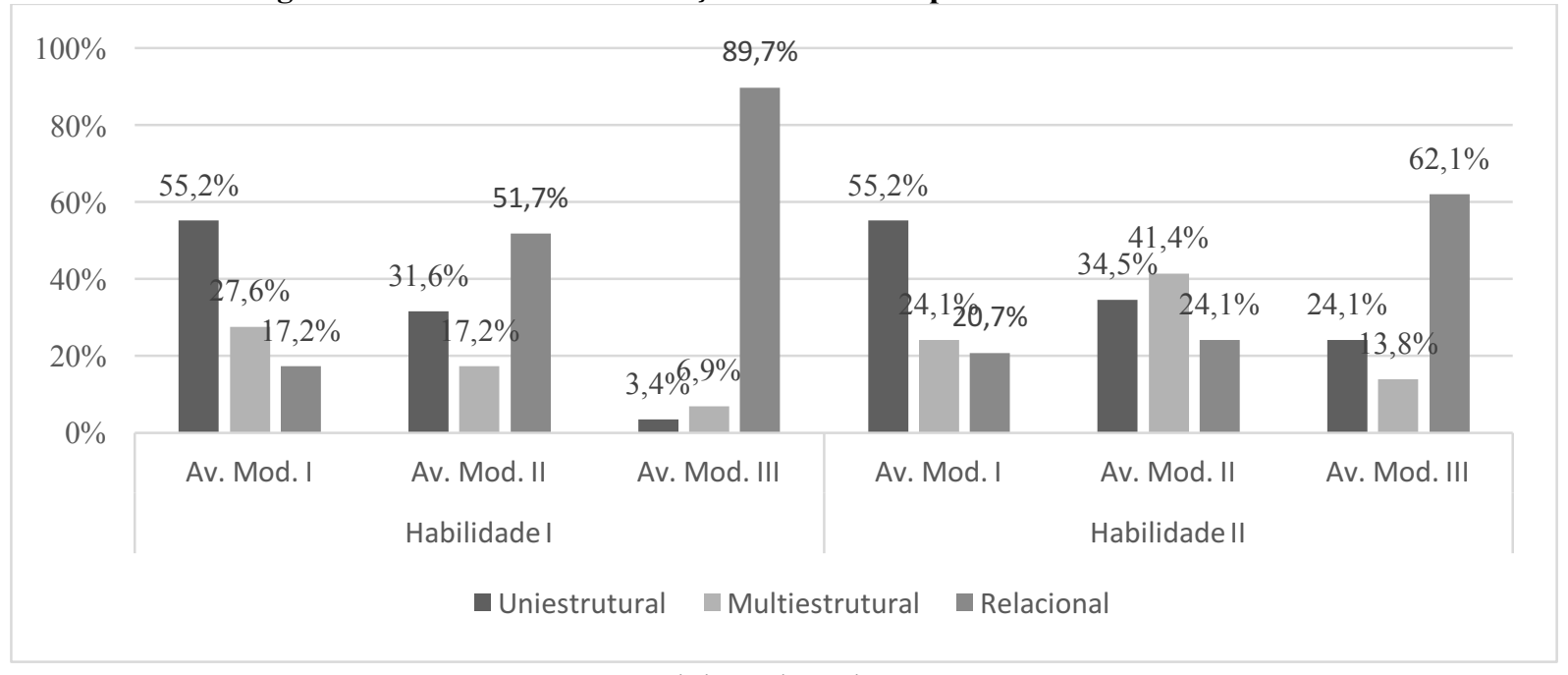

Fonte: Elaborado pelos autores.

Com respeito a questão de pesquisa 2 (QP2), encontramos também evidências de melhorias com respeito a Habilidade 2. Contudo, foram resultados menos expressivos que aqueles obtidos para a Habilidade 1. Isso fica evidente, nos resultados do pré e pós-teste para a Habilidade 2, demonstrados na Figura 3 (lado direito). Como pode ser observado, ao final do estudo, no pós-teste, apenas $55,2 \%$ dos estudantes alcançaram o nível relacional para a Habilidade 2, significando que apenas um pouco mais da metade da turma conseguia elaborar a equação algébrica e manipular adequadamente as operações aritméticas para prover uma solução correta. O pós-teste também revelou que, ao final do estudo, 37,9\% dos estudantes encontravam-se ainda no nível multiestrutural. Portanto, não conseguindo elaborar a equação algébrica para figuras complexas e cometendo erros nos procedimentos de cálculos para resolução da equação.

Os resultados de rendimento dos estudantes na realização das avaliações modulares para a Habilidade 2 são apresentados na Figura 4 (lado direito). Como pode ser observado, nos Módulos I e II, o nível relacional é alcançado por menos de 30\% dos estudantes. Neste nível da taxonomia, o melhor desempenho dos estudantes foi obtido apenas no Módulo III, por 62,1\% dos estudantes. Cabe destacar, porém, que deste total, apenas 20,7\% deles alcançaram o conceito ótimo, isto porque, embora a equação algébrica tenha sido definida de forma correta, o cálculo apresentava algum procedimento incorreto. 
Embora seja esperado que alunos nas séries finais do ensino fundamental possuam domínio na manipulação das operações aritméticas, não é o que se vê na prática de sala de aula. Este problema é evidente não apenas nos instrumentos de avaliação internacional e nacional como o PISA e Prova Brasil, como também por pesquisadores da área (LOPES, 2007).

Com respeito a questão de pesquisa 3 (QP3), destacamos as seguintes dificuldades:

Dificuldades com programação. A montagem dos modelos robóticos foi uma atividade prática na qual os alunos se engajaram mais facilmente, até porque esta atividade é mais lúdica e lembra as brincadeiras de montagem de blocos, típicas da infância. Contudo os alunos sentiram mais dificuldades na programação dos robôs, havendo maior ocorrência de erros e retrabalho na correção dos códigos. Apenas 17\% dos estudantes afirmaram ter gostado de programar os robôs. Neste estudo, a dificuldade com a programação é justificada em virtude de ter sido a primeira experiência dos estudantes com programação. Acreditamos que o uso recorrente das atividades de robótica pode amenizar as dificuldades de programação e também favorecer o desenvolvimento do raciocínio lógico e das estratégias de resolução de problemas pelos alunos. Habilidades muito importantes para o domínio da Matemática.

Limitações do Planejamento de Ensino. Pelo estudo realizado, acreditamos que seja necessário incluir em nosso planejamento de ensino a utilização de outros recursos para favorecer a aprendizagem, inclusive, prevendo dificuldades com conteúdos básicos de Matemática. Assim, acreditamos que a adoção de Plataformas Adaptativas como a Khan Academy $^{3}$, por exemplo, pode ajudar a mitigar as dificuldades dos alunos com as operações aritméticas e outros conteúdos da Matemática. Além de incentivá-los a uma prática de estudo autônomo. Esta Plataforma disponibiliza gratuitamente vídeos e exercícios para diferentes assuntos da Matemática e de outras áreas do conhecimento, e permite que professores possam acompanhar o desempenho de suas turmas.

Limitações de Infraestrutura. O espaço físico do laboratório de informática da escola foi inadequado para as atividades. Além do espaço dos computadores, era necessária uma área de circulação para que os estudantes pudessem testar os movimentos dos robôs sobre os circuitos (impressos em lona de PVC com uma dimensão de 1,2 x 0,90 m). Para amenizar essa limitação do espaço físico, utilizamos o pátio do refeitório da escola para a realização da atividade mencionada.

\section{Considerações Finais}

Neste artigo apresentamos um estudo sobre a integração da Robótica Educacional para o ensino das Relações Métricas do Triângulo Retângulo, considerando alunos do $9^{\circ}$ ano do Ensino Fundamental. Os resultados obtidos demonstram que a Robótica Educacional foi mais efetiva no desenvolvimento da habilidade de identificação dos elementos geométricos em uma representação gráfica do que no desenvolvimento da habilidade para elaboração e resolução da equação algébrica tendo em vista a solução dos problemas propostos.

$\mathrm{Na}$ literatura observamos um número crescente de relatos de utilização de Robótica Educacional na Educação Básica para o ensino de conteúdos de Matemática (ALMEIDA, 2007; FAISAL; KAPILA; ISKANDER, 2012). Estes relatos reforçam os resultados obtidos em nosso estudo, sobre a contribuição de Robótica para desenvolver a percepção das formas geométricas.

Como produto deste trabalho, organizamos um Caderno de Aplicação de Robótica Educacional para o Ensino de Matemática com enfoque nas Relações Métricas do Triângulo Retângulo ${ }^{4}$. Este Caderno está organizado em três partes: (1) contendo as orientações para elaboração de problemas matemáticos com o uso de Robótica Educacional; (2) contendo

\footnotetext{
${ }^{3}$ https://pt.khanacademy.org/

${ }^{4}$ https://goo.gl/o95WZW
}

V. $14 \mathrm{~N}^{\circ}$ 2, dezembro, 2016 
indicações sobre kits educacionais de Robótica e outros recursos de auxílio aos docentes; (3) fornecendo orientações para a aplicação do planejamento de ensino desenvolvido, no formato de um curso.

Como trabalhos futuros apontamos a necessidade de replicar este estudo em outras escolas e de investigar a adaptação deste planejamento de ensino no estudo de outros temas da Geometria na Educação Básica.

\section{Referências Bibliográficas}

ALMEIDA, M. As Possibilidades da Robótica Educacional para a Educação Matemática. Revista da Escola Regional de Informática UFRPE. Curitiba. V2, nº 2. p. 366-394, 2007.

BIGGS, J.; TANG, C. Teaching for Quality Learning at University. 4a. ed. Berkshire, England: Society for Research into Higher Education \& Open University Press, 2011.

BLIKSTEIN, P. O Pensamento Computacional e a Reinvenção do Computador na Educação. Disponível em: <https://goo.gl/A7jPru> , acesso em 29/05/2014.

BRABRAND, C.; DAHL, B. Constructive alignment and the solo taxonomy: a comparative study of university competences in computer science vs. mathematics. In: AUSTRALIAN COMPUTER SOCIETY, INC. Proceedings of the Seventh Baltic Sea Conference on Computing Education Research-Volume 88, p. 3-17. Darlinghurst, Austrália, 2007.

BRASIL. Secretaria de Educação Fundamental. Parâmetros Curriculares Nacionais: Matemática / Secretaria de Educação Fundamental. Brasília: MEC / SEF, 1998. 148 p. 1. Parâmetros curriculares nacionais. 2. Matemática: Ensino de quinta a oitava séries.

CEIA, M.; FILIPE, A.; SANTOS, C. Provas de aferição e exames: a qualidade das questões de álgebra. Atas do Encontro de Investigação em Educação Matemática, p. 149-171, 2011.

COSTA JR., A. O.; GUEDES, E. B. Uma Análise Comparativa de Kits para a Robótica Educacional. Anais do $\mathbf{2 3}^{\circ}$ Workshop Sobre Educação em Computação. Recife, Pernambuco, 2015.

FAISAL, A., KAPILA, V. \& ISKANDER, M. Using Robotics to Promote Learning In Elementary Grades. In: American Society for Engineering Education, New York. 2012.

LOPES, Silvia Ednaira. Alunos do ensino fundamental e problemas escolares: leitura e interpretação de enunciados e procedimentos de resolução. Centro de Ciências ExatasPrograma de pós-graduação em educação para a ciência e o Ensino de Matemática. Maringá: Universidade Estadual de Maringá, 2007.

PAPERT, Seymour. A máquina das crianças: repensando a escola na era da informática. Porto Alegre: Artmed, 2008.

PEREIRA, Jamerson dos Santos; OLIVEIRA, Andreia Maria Pereira de. Manipulable materials and engagement of students in math classes involving topics of geometry. Ciênc. educ. (Bauru), Bauru, v. 22, n. 1, p. 99-115, mar. 2016. Disponível em $<$ https://goo.gl/nZ6QUA $>$, acesso em 20 set. 2016. 
RESENDE, Giovane; MESQUITA, Maria da Glória B.F. Principais dificuldades percebidas no processo ensino-aprendizagem de Matemática em escolas do município de Divinópolis. Educação Matemática Pesquisa, v. 15, n. 1, 2013.

STEVENS, D.D; LEVI, A. Introduction to rubrics: an assessment tool to save grading time, convey effective feedback, and promote student learning. 1st ed. Sterling, Virginia, 2005. 